\title{
Evaluation of the correlation between perfusion index and prognosis in patients with chronic obstructive pulmonary dis-
}

\section{ease}

\author{
Mehmet Demir $^{1} \odot$, Başar Cander ${ }^{2} \odot$, Barış Murat Ayvacı ${ }^{3} \odot$ \\ ${ }^{1}$ Department of Emergency Medicine, University of Health Sciences, Bursa Yüksek Ihtisas Training and Research Hospital, Bursa, \\ Turkey \\ ${ }^{2}$ Department of Emergency Medicine, University of Health Sciences, Kanuni Sultan Süleyman Training and Research Hospital, İstanbul, \\ Turkey \\ ${ }^{3}$ Department of Emergency Medicine, Yeditepe University Faculty of Medicine, Istanbul, Turkey
}

\begin{abstract}
Objectives: This study aims to investigate whether perfusion index (PI) values, which are measured noninvasively, affect emergency management, especially in hospitalization and discharge decision in patients with Chronic Obstructive Pulmonary Disease (COPD).

Methods: Patients who were admitted to the emergency department of Okmeydanı Training and Research Hospital with a COPD exacerbation in 3-months period and who volunteered to participate were included in the study. Vital parameters and PI values of the patients at the time of admission, at the first, second and third hour of the admittance and at the time of hospitalization (in the case of hospitalization) were recorded. The patients were treated for COPD exacerbation according to the Global Initiative for Chronic Obstructive Lung Disease 2011 guide and the decision of discharge, hospitalization in the emergency department, andhospitalization in the intensive care unit was taken based on the relevant guideline.

Results: A total of 57 patients were included in the study. Of the patients, 45 (78.9\%) were male. The mean age of the patients was $65.65 \pm 9.90$ years. There was no statistically significant difference in arrival vital parameters and PI in terms of the gender $(p>0.05)$. The change between PI values at the time of admission and the first hour in the patients admitted to intensive care unit was found to be significantly lower compared to patients who were hospitalized in the emergency department or discharged $(p=0.035 ; p=0.033)$. The difference between the PI values at the time of admission and at the third hour of the follow up of the discharged patients was found to be significantly higher compared to the hospitalized patients $(p=0.035)$. There was no statistically significant difference between the arrival PI measurements in terms of the presence of comorbid diseases $(p>0.05)$.

Conclusions: Considering the hourly changes, the PI values of patients admitted to the emergency department with COPD exacerbation may be helpful in predicting the decision of discharge, hospitalization in the emergency department or intensive care unit.
\end{abstract}

Keywords: Emergency department, chronic obstructive pulmonary disease, perfusion index

How to cite this article: Demir M, Cander B, Ayvacı BM. Evaluation of the correlation between perfusion index and prognosis in patients with chronic obstructive pulmonary disease. Eur Res J 2022;8(1):16-23. DOI: 10.18621/eurj.814761

Address for correspondence: Mehmet Demir, MD., University of Health Sciences, Bursa Yüksek Ihtisas Training and Research Hospital, Department of Emergency Medicine, Mimar Sinan Mah., Ylldirlm, 16290,Bursa,Turkey,E-mail: drdemir27@gmail.com, Tel: +90 5425372627 
$\mathrm{C}$ hronic Obstructive Pulmonary Disease (COPD) is a common, preventable, treatable, chronic and progressive lung disease developing as due to the chronic inflammatory process against harmful gases and particles, particularly cigarette smoke. Inflammation is not only restricted to the lungs, but has systemic features. COPD exacerbation and comorbidities may affect the natural course of the disease $[1,2]$.

COPD is one of the most important causes of morbidity and mortality worldwide. The World Health Organization (WHO) predicts that COPD, the fourth cause of mortality in the world in 2004, will have been the third by 2030 . Within this scope, more than $90 \%$ of morbidity and mortality in low and middle income countries are thought to be related to COPD [3, 4]. Adequate tissue perfusion is vital in maintaining metabolic processes in cells, repairing tissue and developing resistance to infectious organisms [5]. Many clinical studies have demonstrated that early correction of tissue hypoxia in critical patients and providing systemic oxygen support may decrease the incidence of mortality and morbidity [6].

The perfusion index is an indirect and noninvasive measurement of peripheral perfusion. It is calculated with the pulse oximeter by measuring the percentage of the pulsatile signal to the non-pulsatile signal, and both values are obtained from the absorbed infrared light. Perfusion index value may vary depending on the measured area (finger, toe). In the monitoring of peripheral perfusion, Doppler flowmeter, capillary microscopy, transcutaneous oximeter, and sublingual capnometry can be used. However, PI measurement is important in terms of bedside evaluation, easy application, early detection of organ dysfunction, and early intervention [7].

Time is of the essencein the initial resuscitation and treatment of emergency patients. Therefore, the use of non-invasive parameters is recommended as an alternative approach to other methods to identify hemodynamically unstable patients. Non-invasive imaging systems are more appropriate for early identification of hemodynamic status in emergency patients [8].

This study aims to investigate whether non-invasively measured perfusion index (PI) values in COPD patients affect the emergency management, especially on the hospitalization and discharge decision.

\section{METHODS}

The study was designed as a single-center, prospective, cross-sectional, and descriptive study.Prior to the study, ethical approval was obtained from the Turkish Medicines and Medical Devices Agency, Okmeydanı Training and Research Hospital (TRH), Planning Board of Education. The study was conducted with the approval of OkmeydanıTRH Clinical Research Ethics Committee dated 18.11.2014 and numbered 242. The study population consisted of patients admitted to the emergency department of Okmeydanı TRH with COPD exacerbation in 3-months period. For the calculation of sample size we used formula $(\mathrm{n}=\mathrm{Nt} 2 \mathrm{pq} / \mathrm{d} 2(\mathrm{~N}-1)+\mathrm{t} 2 \mathrm{pq})$ and minimum of 50 total amount of cases found.

Patients over 18 years of age with a diagnosis of COPD and admitted to our emergency medicine clinic due to COPD attack and patients who agreed to participate in the study and informed consent form signed by the patients himself or his first degree relative at the time of application to the emergency department were included to the study.

Exclusion criteria of the study were when patients under the age of 18 years old, patients who did not agree to participate in the study and patients who didn't diagnosed with COPD. No patient met these exclusion criteria of the study.

The patients were treated for COPD exacerbation according to the Global Initiative for Chronic Obstructive Lung Disease (GOLD) 2011 guide and the decision of discharge, hospitalization in the emergency department, and hospitalization in the intensive care unit was taken based on the relevant guideline.In patients who were followed up with COPD exacerbation, PI values at the time of admission, at the first, second, and third hour of the admittance, and at the time of hospitalization in the case of hospitalization were measured by a different physician with the Masimo Pulse Co-oximeter Rad-57 from the second, third or fourth finger for at least 10 seconds. Vital parameters at the time of arrival (body temperature, pulse, blood pressure, $\mathrm{O}_{2}$ saturation) as well as age, gender, the presence of comorbid disease and used drugs written on the triage cardwere recorded in the case report form. Therefore, the treatment process and the decision taken about the patient (hospitalization, need for intensive care, discharge) according to the guideline 
suggestions were recorded in the aforementioned form.

Patients over the age of 18 who were diagnosed with COPD and admitted to emergency department due to COPD exacerbation, and whose voluntary consent form could be signed by the patient or a first degree relative at the time of emergency admittance were included in the study. Patients under 18 and who did not agree to participate were excluded.

\section{Statistical Analysis}

In the statistical analysis, Number Cruncher Statistical System 2007 and Power Analysis and Sample Size 2008 Statistical Softwares (Utah, USA) were used. In addition to descriptive statistical methods (Mean, Standard Deviation, Median, Frequency, Rate, Minimum, and Maximum), Mann Whitney U test was used to compare groups having non-normally distributed parameters. Kruskal Wallis Test was used for comparisons of three or more groups not showing normal distribution, and Mann Whitney U test was used to determine the group causing the difference. Wilcoxon signed-rank test was used for intra-group comparisons of groups having non-normally distributed parameters. Fisher-Freeman-Halton test was used to analyze qualitative data. Pearson and Spearman correlation analysis was used to examine the relationships between parameters. $P<0.05$ was considered statistically significant.

\section{RESULTS}

A total of 57 participants were included in the study. The mean age was $65.65 \pm 9.90$ years, the mean pulse rate was $102.37 \pm 16.34$, and the mean body temperature was $36.92 \pm 0.69^{\circ} \mathrm{C}$. The most common comorbidities were hypertension with $35.6 \%(n=21)$ and ischemic heart disease with $33.9 \%(n=20)$ (Table 1).

The length of stay in the emergency service ranged from 1 to 5 hours, with a mean of $2.79 \pm 0.77$ hours. No hospitalization was observed in $75.4 \%(n=43)$ of the cases, while $14.1 \%(n=8)$ were hospitalized in the emergency service and $10.5 \%(n=6)$ were admitted to the intensive care unit.

The arrival PI measurements of the cases ranged from 0.13 to 17 , with a mean of $4.56 \pm 3.58$ (Table 2).

According to the results, pulse, systolic, diastolic and body temperature measurements did not show sta-

Table 1. Distribution of descriptive parameters

\begin{tabular}{|cc|}
\hline Age (years), Mean \pm SD & $65.65 \pm 9.90$ \\
\hline Gender, $\mathbf{n}(\%)$ & \\
\hline Female & $12(21.1)$ \\
\hline Male & $45(78.9)$ \\
\hline Blood pressure (mmHg), Mean \pm SD & \\
\hline Systolic & $147.84 \pm 33.89$ \\
\hline Diastolic & $80.67 \pm 17.80$ \\
\hline Pulse, Mean \pm SD & $102.37 \pm 16.34$ \\
\hline Body temperature (C $\left.{ }^{\mathbf{9}}\right)$, Mean \pm SD & $36.92 \pm 0.69$ \\
\hline Saturation (\%), Mean \pm SD & $88.74 \pm 9.16$ \\
\hline Comorbidities*, $\mathbf{n}(\%)$ & \\
\hline Lung cancer & $1(1.7)$ \\
\hline Diabetes & $6(10.2)$ \\
\hline Hypertension & $21(35.6)$ \\
\hline Ischemic Heart Disease & $20(33.9)$ \\
\hline Congestive Heart Failure & $9(15.3)$ \\
\hline
\end{tabular}

*Multiple options are marked 
Table 2. Distribution of the length of stay, hospitalization status and PI measurements

\begin{tabular}{lcc}
\hline & $\mathbf{n}$ & Mean \pm SD \\
\hline Arrival PI & 57 & $4.56 \pm 3.58$ \\
$\mathbf{1}^{\text {st }}$ hour PI & 57 & $5.65 \pm 3.48$ \\
$\mathbf{2}^{\text {nd }}$ hour PI & 56 & $5.81 \pm 2.90$ \\
$\mathbf{3}^{\text {rd }}$ hour PI & 36 & $6.00 \pm 3.07$ \\
\hline Hospitalization PI & 14 & $5.57 \pm 3.62$ \\
\hline
\end{tabular}

tistically significant difference in terms of the age distribution of the cases $(p>0.05)$.

The percentage of saturation of patients without hospitalization was found to be significantly higher than those who were hospitalized in the emergency department and the intensive care unit $(p=0.001)$.

There was no statistically significant difference between the distribution of the hospitalization results of the patients according to gender $(p>0.05)$ (Table $3)$.

According to the arrival PI measurement, the mean increase of 1.09in PI measurement at the first hour was found statistically significant $(p=0.001)$. According to the arrival PI measurement, the mean increase of 0.68 in PI measurement at hospitalization was not statistically significant $(p>0.05)$ (Table 4$)$.

The results showed a statistically significant difference between the arrival PI measurements of the cases $(p=0.043)$. According to the results of Mann Whitney U Test conducted to determine the difference, it was found that the arrival PI values of the patients who were hospitalized in intensive care unit were significantly higher than the patients hospitalized in the emergency department $(p=0.039)$. There was no significant difference between other groups $(p>0.05)$.

According to the arrival PI measurement of the patients, it was concluded that there was a statistically

Table 3. Evaluation according to the decision

\begin{tabular}{|c|c|c|c|c|c|}
\hline & & \multicolumn{3}{|c|}{ Decision } & \multirow[t]{2}{*}{$p$ value } \\
\hline & & $\begin{array}{c}\text { No } \\
\text { Hospitalization } \\
(n=43)\end{array}$ & $\begin{array}{l}\text { Emergency Service } \\
\text { Hospitalization } \\
(\mathbf{n}=\mathbf{8})\end{array}$ & $\begin{array}{c}\text { Intensive Care } \\
\text { Hospitalization } \\
\quad(n=6)\end{array}$ & \\
\hline Age & $\begin{array}{l}\text { Min-Max } \\
\text { (Median) }\end{array}$ & $\begin{array}{c}50-83 \\
(66)\end{array}$ & $\begin{array}{l}58-80 \\
(65.5)\end{array}$ & $\begin{array}{l}51-82 \\
(68.5)\end{array}$ & $0.963^{c}$ \\
\hline Pulse & $\begin{array}{l}\text { Min-Max } \\
\text { (Median) }\end{array}$ & $\begin{array}{c}70-140 \\
(100)\end{array}$ & $\begin{array}{l}70-130 \\
(107.5)\end{array}$ & $\begin{array}{c}90-130 \\
(115)\end{array}$ & $0.193^{c}$ \\
\hline SBP & $\begin{array}{l}\text { Min-Max } \\
\text { (Median) }\end{array}$ & $\begin{array}{c}90-220 \\
(143)\end{array}$ & $\begin{array}{c}106-220 \\
(129.5)\end{array}$ & $\begin{array}{c}76-2010 \\
(137)\end{array}$ & $0.931^{c}$ \\
\hline DBP & $\begin{array}{l}\text { Min-Max } \\
\text { (Median) }\end{array}$ & $\begin{array}{c}50-119 \\
(80)\end{array}$ & $\begin{array}{c}50-122 \\
(82.5)\end{array}$ & $\begin{array}{c}45,120 \\
(75.5)\end{array}$ & $0.764^{\mathrm{c}}$ \\
\hline Body temperature & Mean \pm SD & $36.89 \pm 0.65$ & $37.23 \pm 0.95$ & $36.68 \pm 0.55$ & $0.438^{c}$ \\
\hline \multirow[t]{2}{*}{ Saturation (\%) } & $\begin{array}{l}\text { Min-Max } \\
\text { (Median) }\end{array}$ & $\begin{array}{c}78-98 \\
(94)\end{array}$ & $\begin{array}{c}55-96 \\
(85)\end{array}$ & $\begin{array}{c}65-87 \\
(77)\end{array}$ & $\begin{array}{c}0.001^{c *} \\
*\end{array}$ \\
\hline & & n (\%) & n (\%) & n $(\%)$ & \\
\hline \multicolumn{6}{|l|}{ Gender } \\
\hline & Female & $8(66.7)$ & $2(16.7)$ & $2(16.7)$ & $0.648^{d}$ \\
\hline & Male & $35(77.8)$ & $6(13.3)$ & $4(8.9)$ & \\
\hline \multicolumn{6}{|l|}{ Comorbidities } \\
\hline & No & $14(70.0)$ & $3(15.0)$ & $3(15.0)$ & $0.737^{d}$ \\
\hline & Yes & $29(78.4)$ & $5(13.5)$ & $3(8.1)$ & \\
\hline
\end{tabular}

${ }^{\mathrm{c}}$ Kruskal Wallis Test, ${ }^{\mathrm{d}}$ Fisher Freeman Halton Test, $* * p<0.01, \mathrm{SBP}=$ Systolic Blood Pressure, DBP $=$ Diastolic Blood Pressure 
significant difference between the changes at the first hour PI measurement ( $p=0.049)$. According to the arrival PI measurement of patients in intensive care unit, the change in PI measurement at the first hour was found to be significantly lower than those without hospitalization and who were hospitalized in the emergency department $(p=0.035)$. There was no significant difference between other groups $(p>0.05)$.

The results demonstrated no statistically significant difference between the changes in the second hour PI measurement according to the arrival PI measurement $(p>0.05)$. However, it was seen that there was a statistically significant difference between the changes in the third hour PI measurement according to the arrival PI measurement ( $p=0.045)$. In terms of the arrival PI measurement, the change in the third hour PI measurement of the non-hospitalized patients was found to be significantly higher than the patients who were hospitalized in the emergency department $(p=0.035)$. There was no significant difference between other groups $(p>0.05)$ (Table 5).

The positive correlation between arrival PI measurements and hospitalization PI measurements of the patients participating in the study (increasing hospitalization PI values with increasing arrival PI values)at $\% 73.5$ level was found to be statistically significant ( $\mathrm{r}$ $=0.735 ; p=0.003)$ (Fig. 1).

\section{DISCUSSION}

This study aims to investigate the correlation between PI values and hospitalization and discharge decision in COPD patients and to determine whether

Table 4. Evaluation of the difference between arrival PI and the first, second, and third hour PI measurements

\begin{tabular}{llcc}
\hline & \multicolumn{2}{c}{ Perfusion Index (PI) } & $\mathbf{p}^{\mathrm{e}}$ value \\
& Mean \pm SD & Difference & \\
\hline Arrival PI $(\mathbf{n}=\mathbf{5 7})$ & $4.56 \pm 3.58$ & $-1.09 \pm 1.98$ & $\mathbf{0 . 0 0 1 * *}$ \\
\hline $\mathbf{1}^{\text {st }}$ hourPI $(\mathbf{n}=\mathbf{5 7})$ & $5.65 \pm 3.48$ & & \\
\hline Arrival PI $(\mathbf{n}=\mathbf{5 6})$ & $4.34 \pm 3.19$ & $-1.47 \pm 2.18$ & $\mathbf{0 . 0 0 1 * *}$ \\
\hline $\mathbf{2}^{\text {nd }}$ hourPI $(\mathbf{n}=\mathbf{5 6})$ & $5.81 \pm 2.90$ & & \\
\hline Arrival PI $(\mathbf{n}=\mathbf{3 6})$ & $4.09 \pm 3.57$ & $-1.91 \pm 2.49$ & $\mathbf{0 . 0 0 1 * *}$ \\
\hline $\mathbf{3}^{\text {rd }}$ hourPI $(\mathbf{n}=\mathbf{3 6})$ & $6.00 \pm 3.07$ & & \\
\hline Arrival PI $(\mathbf{n}=\mathbf{1 4})$ & $4.88 \pm 4.46$ & $-0.68 \pm 2.35$ & $\mathbf{0 . 3 2 7}$ \\
\hline Hospitalization PI $(\mathbf{n}=\mathbf{1 4})$ & $5.57 \pm 3.62$ & & \\
\hline
\end{tabular}

${ }^{e}$ Wilcoxon Signed Ranks Test, ${ }^{* *} p<0.01$

Table 5. Evaluation according to the decision

\begin{tabular}{|c|c|c|c|c|c|}
\hline & & \multicolumn{3}{|c|}{ Decision } & \multirow[t]{2}{*}{ p value } \\
\hline & & $\begin{array}{c}\text { No } \\
\text { Hospitalization } \\
(n=43)\end{array}$ & $\begin{array}{c}\text { Emergency Service } \\
\text { Hospitalization } \\
(n=8)\end{array}$ & $\begin{array}{l}\text { Intensive Care } \\
\text { Hospitalization } \\
\qquad(n=6)\end{array}$ & \\
\hline Arrival PI & Mean \pm SD & $4.46 \pm 3.30$ & $2.85 \pm 2.73$ & $7.60 \pm 5.08$ & $0.043^{c} *$ \\
\hline $\begin{array}{c}\text { Arrival-1 }^{\text {st }} \\
\text { hour PI }\end{array}$ & Mean \pm SD & $-1.33 \pm 1.85$ & $-1.45 \pm 1.52$ & $1.10 \pm 2.37$ & $0.049^{c} *$ \\
\hline $\begin{array}{c}\text { Arrival-2 }^{\text {nd }} \\
\text { hour PI }\end{array}$ & Mean \pm SD & $-1.72 \pm 2.20$ & $-1.36 \pm 1.25$ & $0.18 \pm 2.54$ & $0.298^{c}$ \\
\hline $\begin{array}{c}\text { Arrival-3 } \\
\text { hour PI }\end{array}$ & Mean \pm SD & $-2.72 \pm 2.23$ & $-0.69 \pm 1.64$ & $-0.23 \pm 3.11$ & $0.045^{\mathrm{c} *}$ \\
\hline
\end{tabular}

${ }^{\mathrm{c} K r u s k a l}$ Wallis Test, ${ }^{*} p<0.05,{ }^{*}{ }^{*} p<0.01$ 


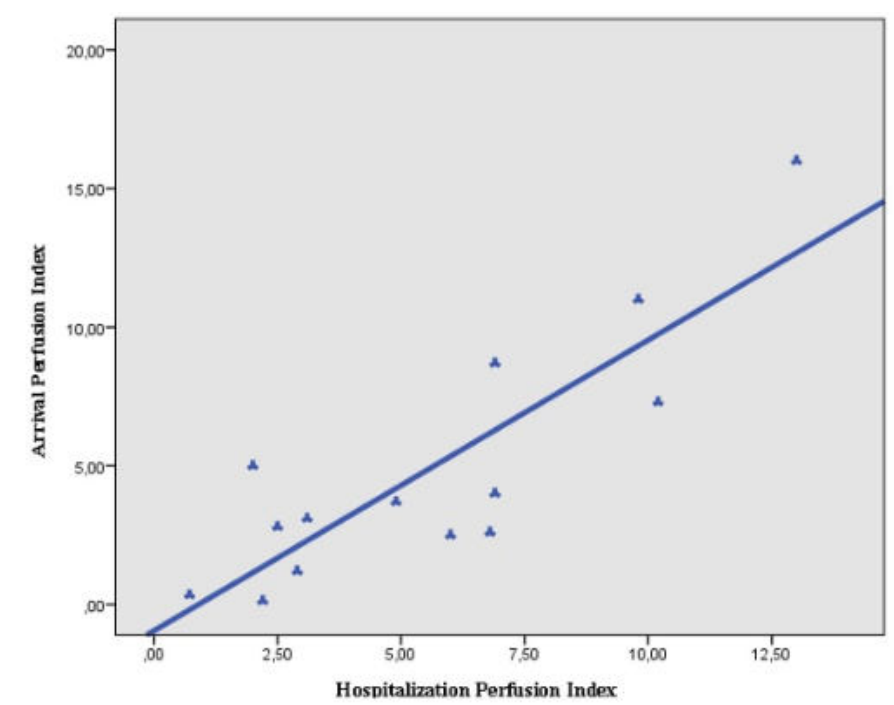

Fig. 1. The Relationship between arrival PI measurement and hospitalization PI measurement.

patients' follow-ups can be performed noninvasively.

The prevalence of COPD also increases with age. In a study conducted by Hong et al. [9], the mean age of the patients with COPD in China was found to be 67.7. Nunez et al. [10] found the mean age of COPD patients living in Europe as 66.6. In a study conducted in our country, the mean age of patients with COPD was found to be 63.5 [11]. In our study, the mean age was 65.6, which is consistent with the literature.

Most studies have shown that the prevalence of COPD in males is higher than that of females $[9,10]$. However, the data obtained in developed countries have revealed that the prevalence is almost equal between females and males, which is thought to reflect changes in the smoking habits [12]. In our study, it was seen that the number of males were considerably higher than that of females. It is thought that this difference is due to the fact that smoking is more common among males in our country.

It can be seen in the literature that approximately two out of every three COPD patients have one or more comorbidities. These include cardiovascular diseases (CVD), lung cancer, and thromboembolic diseases [13]. In the study investigating comorbidity prevalence in COPD patients, it was found that CVD was 2 times and hypertension was 1.6 times higher than normal population, and more hospitalization was observed in those patients. In addition, it was observed that the frequency of diabetes increased with COPD, even in the mild stage [14]. In a study investigating heart failure in patients with COPD, the frequency of heart failure associated with coronary atherosclerosis was found to be $20 \%$ [15]. Although COPD is an independent risk factor for lung cancer, it increases lung cancer risk 2-5 times compared to smokers without COPD [16]. In a cross-sectional study conducted on 514 patients with COPD in 25 centers in Turkey, at least more than half of the COPD patients were shown to have comorbidities. The most common comorbid diseases were cardiovascular diseases with $30.4 \%$, sleep disorders with $20.2 \%$, and hyperlipidemia with $15.8 \%$ [17]. In our study, one or more comorbid diseases were found in $65 \%$ of the cases.

In hospitals, different diagnostic models have been used for the last thirty years to predict the mortality of patients, particularly in adult intensive care patients [18]. Although many invasive and non-invasive methods have been used, there are no studies in the literature revealing the relationship between perfusion index with hospitalization and discharge of patients with COPD exacerbation.

The mean arrival perfusion index of the patients in this study was found to be 4.56.In a study investigating the non-invasive examination of peripheral perfusion in intensive care patients, Lima et al. [19] compared 108 healthy adult and 37 intensive care patients and found the critical PI value as 1.4. They concluded that the values below this value suggest the presence of poor peripheral perfusion [19]. However, the device used in that study was different from the Masimo Pulse Co-Oximeter Rad-57 (The device used in our study), the range of values to be measured were between 0.3 and 10.0. In that study, a threshold value for PI could not be determined due to the absence of a statistically significant difference between the hospitalized and discharged patients. This may be due to the fact that the cases were only COPD exacerbation cases and the number of the cases was relatively low. In a study comparing invasive and non-invasive methods to demonstrate peripheral circulatory disorders in intensive care patients, changes in peripheral perfusion for poor prognosis were found to be a better indicator than fingertip oxygen saturation [20]. In another study investigating whether PI values would be used as a prognostic indicator in intensive care patients, it was concluded that patients with low PI values had organ failure faster [7]. Unlike the other studies, there was no statistically significant difference between admission PI values of the discharged patients and patients 
hospitalized in the emergency department or intensive care unit, who can be considered as critical patients. In a study investigating the relationship between PI values and mortality in intensive care patients in 2013, it was concluded that perfusion index values were effective in predicting mortality [21]. During this study, no mortality was seen inthe patients with COPD exacerbation who were admitted to the emergency department. Long-term patient follow-up was not performed in the study. Therefore, its relationship with mortality could not be determined.

In addition to the studies favoring the perfusion index to predict the perfusion status and mortality of the patients, there are also studies claiming the opposite. In a study, the effect of perfusion worsening due to the sepsis on pulse oximetry was questioned and whether the perfusion index is a marker of poor peripheral perfusion was investigated. It was reported in that study that the perfusion index of anesthetized rabbits was not useful in terms of increased risk [22]. Similarly, in our study, the arrival PI values of the patients admitted to intensive care unit were found to be significantly higher than the arrival PI values of the patients who were hospitalized in the emergency department or discharged.

\section{Limitations}

This study may have some limitations. First of all, the most important limitationsof this studyare that the study is single-centered and the number of patients is low.Because of some of the blood gases taken from the patients were venous and the others were arterial blood gases, standardization could not be done, so they were not included in the study. The normal value range or a cut-off value fort he PI was not calculated.

\section{CONCLUSION}

With the first hour PI changes, it is possible to predict that the patient's response to the treatment may be poor and the patient may be taken to the intensive care unit. Considering the third hour PI of the patients, it may be possible to predict the decision of discharge or hospitalization. In conclusion, there is no significant relationship between the arrival PI values and the discharge or hospitalization of the patients admitted to the emergency department with COPD exacerbation.
The number of studies investigating the relationship between PI and prognosis is low in the literature and it is thought that it will be appropriate to conduct studies in larger series.

\section{Authors' Contribution}

Study Conception: MD, BC; Study Design: MD, BC, BMA; Supervision: MD, BC, BMA; Funding: MD, BC, BMA; Materials: MD, BC, BMA; Data Collection and/or Processing: MD, BC; Statistical Analysis and/or Data Interpretation: MD, BC, BMA; Literature Review: MD, BC, BMA; Manuscript Preparation: $\mathrm{MD}, \mathrm{BC}, \mathrm{BMA}$ and Critical Review: $\mathrm{MD}, \mathrm{BC}$, BMA.

\section{Conflict of interest}

The authors disclosed no conflict of interest during the preparation or publication of this manuscript.

\section{Financing}

The authors disclosed that they did not receive any grant during conduction or writing of this study.

\section{REFERENCES}

1. Jiang Y, Liu F, Guo J, Sun P, Chen Z, Li J, et al. Evaluating an intervention program using WeChat for patients with chronic obstructive pulmonary disease: randomized controlled trial. J Med Internet Res 2020;22:e17089.

2. Li XJ, Kang Y, Wang RR, Liao XL, Ou XF, Liu J, et al. The effects of safflower yellow on acute exacerbation of chronic obstructive pulmonary disease: a randomized, controlled clinical trial. Evid Based Complement Alternat Med 2019;2019:5952742. 3. GBD 2016 Causes of Death Collaborators. Global, regional, and national age-sex specific mortality for 264 causes of death, 1980-2016: a systematic analysis for the Global Burden of Disease Study 2016. Lancet 2017;390:1151-210.

4. Cai L, Wang XM, Fan LM, Shen JR, Liu YN, Golden AR. Socioeconomic variations in chronic obstructive pulmonary disease prevalence, diagnosis, and treatment in rural Southwest China. BMC Public Health 2020;20:536.

5. Gottrup F. Physiology and measurement of tissue perfusion. Ann Chir Gynaecol 1994;83:183-9.

6. Rady MY, Rivers EP, Nowak RM. Resuscitation of the critically III in the ED: responses of blood pressure, heart rate, shock index, central venous oxygen saturation, and lactate. Am J Emerg Med 1996;14:218-25.

7. Lima A, Jansen TC, van Bommel J, Ince C, Bakker J. The prognostic value of the subjective assessment of peripheral perfusion in critically ill patients. Crit Care Med 2009;37:934-8.

8. Shoemaker WC, Wo CC, Chan L, Ramicone E, Kamel ES, 
Velmahos GC, et al. Outcome prediction of emergency patients by noninvasive hemodynamic monitoring. Chest 2001;120:52837.

9. Hong Y, Graham MM, Southern D, McMurtry MS. The association between chronic obstructive pulmonary disease and coronary artery disease in patients undergoing coronary angiography. COPD 2019;16:66-71

10. Nunez A, Marras V, Harlander M, Mekov E, Esquinas C, Turel M, et al. Association between routine blood biomarkers and clinical phenotypes and exacerbations in chronic obstructive pulmonary disease. Int J Chron Obstruct Pulmon Dis 2020;15:68190.

11. Kar S, Zengin N. [Examining the state of health in patients with COPD according to sociodemographic and disease-related characteristics]. . J Pro Health Res 2019;1:1-7. [Article in Turkish]

12. Dalal AA, Christensen L, Liu F, Riedel AA. Direct costs of chronic obstructive pulmonary disease among managed care patients. Int J Chron Obstruct Pulmon Dis 2010;5:341-9. 13. Sin DD, Anthonisen NR, Soriano JB, Agusti AG. Mortality in COPD: role of comorbidities. Eur Respir J 2006;28:1245-57. 14. Mannino DM, Thorn D, Swensen A, Holguin F. Prevalence and outcomes of diabetes, hypertension and cardiovascular disease in COPD. Eur Respir J 2008;32:962-9.

15. Rutten FH, Cramer MJ, Lammers JW, Grobbee DE, Hoes AW. Heart failure and chronic obstructive pulmonary disease: An ignored combination? Eur J Heart Fail 2006;8:706-11.

16. Mannino DM, Aguayo SM, Petty TL, Redd SC. Low lung function and incident lung cancer in the United States: data From the First National Health and Nutrition Examination Survey follow-up. Arch Intern Med 2003;163:1475-80.

17. Kuyucu T, Guclu SZ, Saylan B, Demir C, Senol T, Guner S, et al. A cross-sectional observational study to investigate daily symptom variability, effects of symptom on morning activities and therapeutic expectations of patients and physicians in COPDSUNRISE study. Tuberk Toraks 2011;59:328-39.

18. Keegan MT, Gajic O, Afessa B. Severity of illness scoring systems in the intensive care unit. Crit Care Med 2011;39:163-9. 19. Lima AP, Beelen P, Bakker J. Use of a peripheral perfusion index derived from the pulse oximetry signal as a noninvasive indicator of perfusion. Crit Care Med 2002;30:1210-3.

20. Lima A, van Bommel J, Sikorska K, van Genderen M, Klijn E, Lesaffre E, et al. The relation of near-infrared spectroscopy with changes in peripheral circulation in critically ill patients. Crit Care Med 2011;39:1649-54.

21. Acar Y. The effectiveness of peripheral perfusion index in predicting mortality and perfusion status of patients [Thesis]. GATA; 2012.

22. Hummler HD, Engelmann A, Pohlandt F, Högel J, Franz AR. Decreased accuracy of pulse oximetry measurements during low perfusion caused by sepsis: Is the perfusion index of any value? Intens Care Med 2006;32:1428-31. 